\title{
POESIA E MORTE: UMA LEITURA PSICANALÍTICA DE MANUEL BANDEIRA
}

\author{
Maurício Silva*
}

$\int$

ndubitavelmente, a morte é um dos motivos mais caros às expressões artísticas de toda natureza, e na literatura esta afirmação é tão mais verdadeira quanto mais nos aprofundamos no chamado estudo dos temas literários (Stoffgeschichte) que a Literatura Comparada tão bem soube revelar e definir.

No âmbito restrito da Literatura Brasileira, este tema pode ser facilmente rastreado, emergindo muitas vezes como o principal assunto tratado por seus autores, desde os mais antigos até aqueles que - por falta de um termo mais preciso ou simplesmente por acomodação cronológica - podem ser chamados genericamente de contemporâneos: em todos eles, a morte enquanto motivo literário surge ora como um mero apêndice temático, ora como o centro mesmo de toda a criação. Neste sentido, ela se impôs verdadeiramente como um dos mais fecundos temas tratados por nossos poetas e romancistas, inclusive sendo beneficiada - na poética universal - com uma composição literária toda própria: a elegia, que na sua modalidade mais plangente (o treno) costuma ver a morte como matéria privilegiada de seu canto fúnebre.

* Faculdades Metropolitanas Unidas e Faculdade Radial (São Paulo) 
É particularmente interessante analisar como se processa a relação entre a literatura e a morte num dos mais criativos poetas de nossa expressão literária vernácula: Manuel Bandeira. E, nesta perspectiva, cumpre-nos, entre outras coisas, verificar em que medida esta temática é capaz de condicionar toda uma ligação do poeta com o seu mundo interior e com a realidade externa, fato sintomaticamente refletido na sua produção. Com efeito, já é bastante conhecida a tendência da crítica literária em reconhecer na poesia de Bandeira uma forte presença da morte, definida como um de seus principais temas. Desde os primeiros livros, ainda fortemente marcados por uma estética de natureza parnasiano-simbolista, até as suas obras mais claramente modernistas, a morte pode ser considerada um autêntico leitmotiv de toda a sua produção estética, manifestando-se, contudo, das mais variadas e inesperadas maneiras: ora inusitadamente ligada ao erótico, ora deliberadamente relacionada ao milagre, ora ainda paradoxalmente vinculada à vida.

Não procuraremos, contudo, realizar neste ensaio uma análise exaustiva das múltiplas e variadas relações que a poesia de Bandeira pode estabelecer com o tema da morte, já que tal atitude, além de ser um trabalho desmasiadamente exaustivo, revelar-se-ia uma tarefa extraordinariamente complexa. Isto em função da própria copiosidade desta relação, o que, a nosso ver, torna qualquer pretensão de esgotar o assunto uma indesejável quimera. Antes, optamos por analisar um único poema do autor, o qual possui a vantagem de revelar uma posição exemplar do mesmo diante da morte e, por isso mesmo, adquire um valor emblemático de toda a sua relação com o tema. Trata-se da sua primorosa peça intitulada "A Mário de Andrade ausente":

Anunciaram que você morreu.

Meus olhos, meus ouvidos testemunham:

A alma profunda, não.

Por isso não sinto agora a sua falta.

Sei bem que ela virá

(Pela forf̧a persuasiva do tempo).

Virá súbito um dia,

Inadvertida para os demais.

Por exemplo assim:

À mesa conversarão de uma coisa e outra,

Uma palavra lançada à toa

Baterá na franja dos lutos de sangue,

Alguém perguntará em que estou pensando, 
Sorrirei sem dizer que em você

Profundamente.

Mas agora não sinto a sua falta.

(É sempre assim quando o ausente

Partiu sem se despedir:

Você não se despediu.)

Você não morreu: ausentou-se.

Direi: Faz tempo que ele não escreve.

Irei a São Paulo: você não virá ao meu hotel.

Imaginarei: Está na chacrinha de São Roque.

Saberei que não, você ausentou-se. Para outra vida?

A vida é uma só. A sua continua

Na vida que você viveu.

Por isso não sinto agora a sua falta. ${ }^{1}$

Evidentemente, por mais que nossa análise tenha o intuito de abranger ao máximo o sentido dessa peça, ela não conseguirá encobrir - e nem é este o nosso objetivo - a propriedade que tem toda obra de arte de se revelar como uma verdadeira obra aberta. E se, por um lado, uma leitura restrita do poema limita o alcance de seu significado, por outro, tem o mérito de apresentar uma visão singular do mesmo, contribuindo talvez, de uma maneira incisiva, para maior compreensão do relacionamento de Bandeira com a temática da morte, relacionamento este inegavelmente expresso pelo poema acima transcrito.

Assim sendo, a escolha da perspectiva pela qual se realizará a análise procurou obedecer a um critério igualmente singular, pelo que possui de pessoal e distinto no universo dos estudos literários: trata-se da perspectiva psicanalítica, deliberadamente aplicada à análise da literatura por nos parecer a que melhor pode revelar elementos do inconsciente do autor, imprescindíveis - no nosso entendimento - a um entendimento mais abrangente de sua poesia.

Neste sentido, impõe-se desde já uma discussão de natureza puramente metodológica, a qual apenas encetamos aqui, a saber: a viabilidade de se utilizar uma perspectiva tão particularizada e aparentemente tão distante da literatura num trabalho de análise literária.

1 BANDEIRA, Manuel. Belo belo. In: Estrela da vida inteira: poesias reunidas e poemas traduzidos. Rio de Janeiro: J. Olympio, 1988. p. 174. 
A discussão sobre o assunto é antiga e tem suas raízes na oposição entre a crítica que aceita a utilização de categorias extraliterárias na análise de obras da literatura (categorias biográficas, socias, psicológicas) e a crítica que nega totalmente semelhante posição. Se a primeira tendência parece ter vigorado inconteste desde as primeiras manifestações da crítica moderna, a segunda adquiriu maior força a partir do século 20 , quando as idéias que privilegiam os elementos próprios da estrutura interna das obras literárias são lançadas pelo Formalismo (literaturnost) e pelo New Criticism (close reading), encampadas por uma série de correntes posteriores ou contemporâneas, até serem ambiguamente assumidas pelo Estruturalismo.

Particularmente sobre a perspectiva psicanalítica na análise da obra literária, as discussões passaram por uma série de etapas, ora revelando uma maior aceitação da mesma (C. Baudouin, G. Bachelard), ora uma negação absoluta (John C. Ransom), ora ainda a indefinida situação de um meio-termo (L. Spitzer, N. Frye). ${ }^{2}$

De qualquer maneira, reconhece-se, atualmente, uma tendência da Teoria Literária no sentido de conciliar os radicalismos de qualquer espécie, em função de maior grau de compreensão possível da obra de literatura ${ }^{3}$, posição louvável nos críticos mais conscientes. Afora isto, não se deve esquecer todo um crescente posicionamento crítico que assume definitivamente não apenas a possibilidade, mas principalmente a necessidade de se empregar a perspectiva psicanalítica no desvendamendo da obra literária, segundo o qual seria "impossível comentar uma obra sem fazer menção de processos psicológicos"*4. Embora pareça uma posição radical, há que se notar que, no âmbito dessa perspectiva, é a obra literária em si mesma que importa, limitando-se a Psicologia apenas a uma tarefa auxiliar na compreensão daquela, o que reduz bastante esse aparente radicalismo: é que, para os defensores dessa tendência, com cuja essência argumentativa concordamos, toda atividade que envolva imaginação

2 Cf. MOISÉS, Massaud. Dicionário de termos literários. São Paulo: Cultrix, 1978. Embora discutível, a posição ambígua de alguns autores diante desta questão em especial pode ser claramente percebida, como no caso dos já citados L. Sptizer - que, sobretudo no início de sua carreira, adotou uma posição de aceitação da análise psicológica, para depois renegá-la -e N. Frye - que, embora trabalhe com categorias quase que próprias da perspectiva psicológica (como os arquétipos), não se inibe $\mathrm{em}$ fazer afirmações desse porte: "Percebo que os pormenores são afinal apenas explicáveis dentro da crítica, e reluto em explicar fatos literários com clichês psicológicos." (FRYE, Northrop. Anatomia da critica. São Paulo: Cultrix, [s.d.], p. 92.

3 Particularmente sobre esta questão, cf. SOUZA, Roberto Acízelo de. Teoria da literatura. São Paulo: Ática, 1987.

4 LEITE, Dante Moreira. Psicologia e literatura. São Paulo: Editora Nacional/Secretaria da Cultura, Ciência e Tecnologia, 1977. p. 17. 
(artística ou não) pressupõe uma série de processos inconscientes, os quais só poderiam ser desvendados com o auxílio da Psicanálise. ${ }^{5}$

Daí, portanto, a importância de sua utilização no universo dos estudos literários e nossa decisão em adotá-la sem maiores constrangimentos.

\section{Entre a vida e a morte}

Em qualquer análise que se faça da obra poética de Bandeira, a morte aparecerá inevitavelmente como um dos motivos privilegiados pelo artista, sem o qual é de se acreditar que sua poesia perderia muito em emotividade e originalidade. Daí termos sugerido que este é, sem dúvida alguma, um tema recorrente em toda a sua produção poética.

Mas não é somente este aspecto de sua poesia que merece nossa atenção: é importante ressaltar também, para uma apreensão mais acabada do poema a ser analisado, um fato de natureza puramente biográfica: a amizade que Manuel Bandeira devotava ao igualmente grande poeta modernista Mário de Andrade, amizade esta que pode ser percebida por meio de algumas das poesias que Bandeira teria dedicado ao amigo, seja num ímpeto de criação lúdica ("Variações sobre o nome de Mário de Andrade", em Mafuá do malungo), seja por meio de uma simples referência ao mesmo ("Passeio em São Paulo", em Estrela da tarde), seja ainda numa plangente canção dedicada à sua morte ("A Mario de Andrade ausente", em Belo belo). Talvez tão sintomática da amizade entre os dois artistas quanto estas poesias seja a correspondência que os dois teriam trocado entre si, sobretudo as cartas que Mário escreveu ao companheiro, num contínuo ato de dedicação e declaração de amizade. ${ }^{6}$ E da parte de Bandeira, há muito de revelador dessa amizade na sua inesquecível obra autobiográfica. ${ }^{7} \mathrm{E}$ o poema em questão revela não somente uma certa prevalência do tema da morte em sua obra, como também todo o significado dessa imarcescível amizade entre os dois artistas.

A começar pelo título, pode-se perceber algumas características do poema que irão contribuir sobremaneira para uma melhor avaliação e compreensão do mesmo: trata-se, em primeiro lugar, de uma dedicatória a alguém que, por força do Destino e da natural evolução dos seres, encontra-se fisicamente

5 BELLEMIN-NOËL, Jean. Psicanálise e literatura. São Paulo: Cultrix, 1983; cf. também CARDOSO FILHO, Antônio. Literatura e psicanálise. Letras de Hoje, Ponto Alegre, n. 53, p. 83-91, set. 1983.

6 ANDRADE, Mário de. Cartas a Manuel Bandeira. Rio de Janeiro: Edjouro, [s.d.].

7 BANDEIRA, Manuel. Itinerário de Pasárgada. Rio de Janeiro: Editora do Autor, 1966. 
ausente. Há que se dar uma atenção especial para o emprego do termo ausente no lugar de qualquer outro que esclarecesse melhor a situação real do amigo (morrer, falecer, expirar): é que, já no título do poema, Bandeira nos revela uma de suas atitudes mais freqüentes ao longo de toda a peça, e que terá uma significação especial no corpo da mesma - a substituição da morte pela ausência.

Uma leitura rápida do poema nos revela uma série de elementos que, posteriormente, nos auxiliarão numa análise mais profunda do mesmo. A utilização do verso livre, por exemplo, uma de suas características mais enfatizadas pela crítica, já nos indica que estamos num universo peculiar: trata-se, antes de mais nada, de uma poesia da fase madura de Bandeira, e sugere uma relativa liberdade na expressão dos seus sentimentos. Mas no que concerne à expressão lingüística do poema, o destaque fica mesmo por conta do fato de se tratar de uma espécie de poema-narração ou de um poema em prosa, onde tanto a linguagem coloquial utilizada quanto a funda impressão de estarmos diante de um descompromissado relato já nos revelam uma nova dimensão do poema: parece tratar-se de uma simples história que, subtraída de um fato corriqueiro do cotidiano (a morte de um conhecido) adquire uma fascinante e inatingivel força lírica. Cotidiano e reminiscência entrelaçam-se no poema, $\mathbf{e}$ assim o poeta vai criando um quadro vigoroso do seu sentimento, onde a emotividade adquire um valor insuperável.

Outro elemento que, logo de início, a leitura do poema revela diz respeito ao embate entre elementos contrários, travado no corpo do mesmo: percebe-se, neste sentido, tanto a oposição entre a realidade da morte (incidida sobre a figura de Mário de Andrade) e o desejo de vida (revelado por Manuel Bandeira) quanto a oposição - já aludida aqui - entre um fato irreversível (morte) e uma realidade que se quer modificável (ausência). Tais embates vão se desdobrar ao longo de toda a peça, a qual requer, desde já, uma análise mais crítica e penetrante.

Podemos, em primeiro lugar, distinguir três partes semi-independentes do poema de Bandeira, as quais parecem se destacar pela coesão das idéias nelas contidas: a primeira parte trata, mais particularmente, do anúncio da morte do amigo e da primeira reação do poeta diante da notícia (primeiros quatro versos); a segunda parte contém uma reflexão do poeta a respeito da chegada sutil do sentimento de falta e da saudade em relação ao amigo (do quinto ao décimo nono verso); finalmente, a terceira parte reflete uma consciência maior da ausência do amigo estimado por parte do poeta.

É sintomático o fato de a primeira parte do poema iniciar com uma oração cujo sujeito é indeterminado, apontando para um recurso freqüente no poema em questão: a eliminação de qualquer indivíduo estranho ao acontecimento narrado no corpo do poema. $\mathrm{Na}$ verdade, não importa quem anunciou, mas, sim, 
o que e para quem se anunciou o fato concreto da morte. Ademais, a disposição do primeiro verso, isolado dos demais por um brusco ponto final, contribui ainda mais para o impacto de uma notícia por natureza comovente: nada parecido com as tergiversações e os melindres que o anúncio de uma notícia semelhante requer do bom-senso. Mais interessante que isso é a reação do poeta diante do anúncio inesperado: verifica-se uma imediata distinção entre realidade (representada pelo corpo) e idealidade (representada pela alma). É neste sentido que podemos entender o fato de os olhos e os ouvidos do poeta testemunharem $o$ anúncio, mas não a sua "alma profunda". E o final igualmente inusitado: o poeta declara não sentir a falta do amigo naquele instante, e isto exatamente pelo fato de ter conseguido alçar a realidade da morte ao nível do ideal ("por isso, não sinto agora a sua falta").

O impacto causado pelos primeiros versos tem sua razão de ser: sensibilizado pela notícia inesperada e indesejada, o poeta reage como qualquer ser humano talvez reagisse diante da perda de um ente querido - negando o fato. Mas, ao mesmo tempo, elevando a realidade da morte para o universo espiritual (o reino da alma profunda), o poeta consegue estabelecer imediatamente um contato íntimo com o leitor, fazendo com que o mesmo se torne, desde o primeiro momento, cúmplice de seus sentimentos mais secretos. Trata-se, sem dúvida, daquele "indisfarçável ar de família" que toda a poesia de Bandeira parece conter, como Sérgio Buarque de Holanda sagazmente apontou. ${ }^{8}$

A reação emotiva da primeira parte do poema será amainada - na segunda parte - pela consciência que o poeta revela da realidade: qualquer que seja a vontade do poeta, a realidade da morte fala mais alto, e ele sabe que, cedo ou tarde, a falta do amigo há de se manifestar. E chegará de uma forma tão súbita quanto a notícia de sua morte ("Virá súbito um dia,/Inadvertida para os demais"), trazida pela força persuasiva do tempo. A fim de tornar o acontecimento mais íntimo, causando um efeito patético ainda maior, o poeta busca exemplificar a maneira pela qual poderá, um dia, ser inesperadamente assaltado pela falta do amigo. Novamente, a predominância de orações com sujeito indeterminado ("À mesa conversarão...") ou formado por pronome indefinido ("Alguém perguntará..."), como que tornando alheia ao drama vivido pelo poeta toda a realidade circundante, com exceção do leitor. E o exemplo: conversa descompromissada numa mesa de bar, uma palavra lançada à toa, trazendo a lembrança do amigo que partiu e estes versos marcados por uma simplicidade que parece esconder deliberadamente uma carga emotiva arrebatadora:

8 HOLANDA, Sérgio Buarque de. Poesias completas de Manuel Bandeira. In: LOPEZ, Telê Porto Ancona (Org.). Manıel Bandeira: verso e reverso. São Paulo: T. A.Queiroz, 1987. p. 110-114. 
A reação emotiva da primeira parte do poema será amainada - na segunda parte - pela consciência que o poeta revela da realidade: qualquer que seja a vontade do poeta, a realidade da morte fala mais alto, e ele sabe que, cedo ou tarde, a falta do amigo há de se manifestar. E chegará de uma forma tão súbita quanto a notícia de sua morte ("Virá súbito um dia,/Inadvertida para os demais"), trazida pela força persuasiva do tempo. A fim de tornar o acontecimento mais intimo, causando um efeito patético ainda maior, o poeta busca exemplificar a maneira pela qual poderá, um dia, ser inesperadamente assaltado pela falta do amigo. Novamente, a predominância de orações com sujeito indeterminado ("À mesa conversarão...") ou formado por pronome indefinido ("Alguém perguntará..."), como que tornando alheia ao drama vivido pelo poeta toda a realidade circundante, com exceção do leitor. E o exemplo: conversa descompromissada numa mesa de bar, uma palavra lançada à toa, trazendo a lembrança do amigo que partiu e estes versos marcados por uma simplicidade que parece esconder deliberadamente uma carga emotiva arrebatadora:

\section{Alguém perguntará em que estou pensando, Sorrirei sem dizer que em você Profundamente.}

A idéia de que o poeta não sente, neste momento, a falta do amigo ausente é novamente enfatizada, e agora mais do que antes, em função da posição de destaque que o verso correspondente à mesma adquire. E também ressurge a idéia da ausência do amigo, acompanhada do lamento em função de uma partida sem despedida.

Finalmente, a terceira parte do poema torna claro um embate continuamente presente na peça - aquele travado entre a realidade da morte e o desejo que o poeta manifesta de que esta mesma realidade não seja verdadeira. Este embate começa pela observação nuclear de que não se trata de morte, mas de ausência; e continua na disputa travada entre a mente do poeta ("Imaginarei: Está na chacrinha de São Roque") e a dura consciência dos fatos ("Saberei que não, você ausentou-se"). Repentinamente, toda a reflexão acerca da morte/ausência do amigo é inesperadamente rompida por algumas ponderações a respeito da vida do mesmo: como a vida é única, o amigo, embora morto, continuaria vivo na vida que ele viveu. Apesar de parecer complexa, a idéia é simples, e revela novamente uma divisāo entre realidade e idealidade: o amigo, enquanto matéria, morreu; mas tudo o que sua vida teria significado para o poeta 
- isto é, a vida que ele viveu -, continua presente na mente do mesmo. Conclusão: por isso agora o poeta não sente a falta do amigo ausente.

Talvez fique mais fácil entender este final do poema, se atentarmos para estas sintomáticas palavras do próprio Bandeira a respeito de Mário de Andrade: "para um homem como Mário de Andrade não pode haver a morte "que acaba tudo'. Porque sua obra é imperecível..." Aqui, o homem é a obra que ele legou à posteridade $e$, neste sentido, o poeta pernambucano tem razão em dizer que Mário de Andrade efetivamente não morreu.

Podemos destacar, a partir da análise acima realizada, alguns elementos recorrentes e significativos na poesia de Bandeira. $O$ primeiro deles se refere à contínua tentativa de atenuação da morte do amigo, que se dá por meio de dois recursos principais: a substituição da morte pela ausência e a ênfase dada ao não-sentimento da falta do amigo. Com efeito, ausência é um termo de origem latina (absens, particípio de absum) que pela própria etimologia revela o afastamento $(a b)$ da condição existencial ( $s u m$ ), portanto um eufemismo utilizado pelo poeta para atenuar o impacto imediato causado pelo vocábulo morte, que na sua dureza e frialdade parece-nos arrastar para um turbilhão de sentimentos inaceitáveis. Também a confissão contínua de que o poeta não sente, no instante presente, a falta do amigo, desempenha um papel de atenuação da morte, já que - por meio da mesma - o poeta parece querer negar intensamente uma realidade insuportável. ${ }^{10}$ Mais do que isso, o advérbio de tempo agora (presente) contrasta fundamente com os tempos verbais que vigoram nos demais versos (passado e futuro): há, portanto, uma nova disputa no corpo do poema entre o universo real/exterior, quase todo situado no passado e no futuro (o anúncio da morte, a conversa na mesa, a viagem a São Paulo) e o universo emocional/interior, situado no presente e que revela o estado de ânimo do poeta (o nãosentimento da falta do amigo).

É esta disputa, aqui reiterada tantas vezes, o segundo elemento recorrente que destacamos no poema. Nas três partes analisadas, há, em maior ou menor grau, a presença desse embate, que pode se manifestar das mais variadas formas: por meio da oposição entre corpo e alma, da oposição entre o atual nãosentimento e o futuro sentimento da falta do amigo, entre a dura realidade da morte e a realidade atenuada da ausência, entre o que o poeta imagina e o que

9 BANDEIRA, Manuel. Prefácio. In: ANDRADE, op. cit., p. 14.

10 O processo de atenuação aqui aludido diversas vezes é, com efeito, um dos principais recursos poéticos utilizados por Bandeira ao longo de toda a sua produção, com evidente ênfase nas suas primeiras obras, conforme revelam os trabalhos de Norma Goldstein (cf. GOLDSTEIN, N. Seltzer. Do penumbrismo ao modernismo: o primeiro Bandeira e outros poetas significativos. Sāo Paulo: Ática, 1983; . O primeiro Bandeira e sua permanência. In: LOPEZ, op. cit., p. 8-21). 
ele sabe de fato, entre a morte física e a permanência da vida por meio da obra legada.

Assim, através de dois elementos recorrentes desse poema - que, genericamente, podemos chamar de atenuação da morte e embate entre realidade e idealidade - emerge seu primeiro e mais epidérmico sentido: o sentido estético. É a partir do desdobramento destes mesmos elementos que um segundo sentido presente na peça se nos revelará prontamente: o sentido psicológico, que permanece subjacente aos conceitos aqui revelados e com o qual completaremos a abordagem do conjunto de significados que compõem o poema em questão.

\section{Psicanálise: desvendar o poema}

Aprofundando a análise acima esboçada, cumpre abordarmos o poema pela ótica da psicanálise, tal como tínhamos proposto desde o princípio. Para tanto, cabe lembrar que a relação entre a poesia de Bandeira e a psicanálise não é nova, tendo sido já objeto de estudo da crítica em diversas oportunidades, seja por meio de simples alusões à possibilidade de se fazer semelhante estudo ${ }^{11}$, seja através de abordagens mais aprofundadas de sua obra poética. ${ }^{12}$

De qualquer maneira, tentaremos ainda uma vez nos utilizar do cabedal de conhecimentos auferidos da psicanálise, a fim de explorar alguns elementos talvez demasiadamente obscuros da poesia do mestre pernambucano: desvendar o poema em causa por meio da psicanálise é, portanto, o nosso propósito.

Utilizaremos, basicamente, algumas teorias de dois expoentes da psicanálise: S. Freud, cuja abordagem da literatura procura centrar-se no artista, e C. Jung, cuja abordagem centra-se na obra propriamente dita. São perspectivas diversas, mas que, unidas, contribuem para um maior entendimento do nosso poema. De fato, os elementos realçados na análise acima nos levam diretamente para dois tipos distintos de análise. Em primeiro lugar, o que chamamos de tentativa de atenuação da morte, não é senão um verdadeiro processo de negação da morte por parte do poeta, já que, por algum obscuro motivo, o mesmo se sente impelido a não aceitar a realidade tal e qual ela se lhe apresenta. Aliás, verifica-se aqui um dos raros momentos em que Manuel Bandeira toma uma atitude de obstinada oposição à morte, em franco contraste com sua tendência à resignação diante da mesma ${ }^{13}$, o que pode ser facilmente explicado pelo fato de se tratar

11 BOSI, Alfredo. História concisa da literatura brasileira. São Paulo: Cultrix, 1988.

12 PASSOS, Cleusa Rios P. Aspectos de uma leitura psicanalítica: "Rondó do Capitão" de Manuel Bandeira. Cultura Vozes, ano 86, v. 86, n. 3, p. 21-28, maio/jun. 1992.

13 Sobre a habitual resignação não-derrotista de Bandeira diante da morte, cf. VILLAÇA, 
não de sua própria morte, mas da de outrem. Portanto, trata-se de uma atitude visceralmente vinculada, antes, à figura do poeta, do que propriamente à sua obra em si mesma, motivo pelo qual algumas das teorias psicanalíticas elaboradas por Freud poderão ser aqui empregadas.

Em segundo lugar, o que destacamos como embate entre realidade e idealidade não reflete senão a coexistência de elementos relacionados ao consciente e ao inconsciente do poeta, os quais, na medida do possível, se explicitam no corpo do mesmo poema. Daí a utilização - quase imperativa - de algumas das teorias formuladas por Jung. Aliás, semelhante coexistência já fora descompromissadamente revelada em maior ou menor grau pela crítica. ${ }^{14}$

Há muitas possibilidades de aplicação das teorias elaboradas por Freud na literatura em geral - como as relações que o pensador vienense estabeleceu entre a obra de arte e a sublimação - ou na poesia de Bandeira em particular, se nos lembrarmos que - como acontece com as teorias freudianas - sua produção também nos revela um freqüente contraste entre as pulsões da vida e da morte. ${ }^{15}$ Mas não é esta a relação que buscamos estabelecer aqui entre a duas obras. Mais de acordo com os nossos propósitos se revelam as teorias de Freud sobre a utilização pelo ego dos chamados mecanismos de defesa (Abwehrmechanismen), estudados a partir de 1893.

Tais estudos, que se iniciam com a relação inovadora entre o histerismo e o eventual acometimento de um trauma psíquico ${ }^{16}$, se desenvolvem no sentido de apontar reações diversas diante de uma situação indesejável ${ }^{17}$, entre as quais a recusa da realidade. ${ }^{18}$ Assim, recusar um fato real - mas indesejável, posto que traumatizante - seria um dos possíveis mecanismos de defesa elaborados pelo ego, num complexo processo de auto-preservação.

Alcides. O resgate íntimo de Manuel Bandeira. In: LOPEZ, op. cit., p. 29-32.

14 Por exempo, LINS, Álvaro. Crítica literária: poesia. In: LOPEZ, op. cit., p. 115-121, para quem Bandeira procura, na sua poesia, harmonizar "as forças inconscientes da inspiração e a força disciplinadora da razão".

15 Sobre as pulsōes da vida e da morte na obra de Freud, cf. ARMONY, Naham. Eros e Tanatos. Humanidades, Universidade de Brasília, v. 7, n. 2, p. 117-121, 1991. Sobre a possibilidade de aplicação das teorias freudianas à literatura, cf. KOFMAN, Sarah. L'enfance de l'art: une interprétation de l'esthétique freudienne. Paris: Galilée, 1985.

16 FREUD, Sigmund. Sobre o mecanismo psíquico dos fenômenos histéricos: uma conferência (1893). In: Obras completas. Trad. de Margarida Salomāo. Rio de Janeiro: Imago, 1976. v. 3, p. 37-52.

17 Id., As neuropsicoses de defesa (1894). Ibid., p. 55-73. Uma fundamentação clínica para as teorias expostas neste artigo é dada, posteriomente, pelo autor em Id., Novos comentários sobre as neuropsicoses de defesa (1896). Ibid., p. 183-211.

18 Id. A divisão do ego no processo de defesa (1938/1940). Ibid., trad. de José Octávio de Aguiar Abreu, v. 23, p. 307-312. 
Ora, não é difícil percebermos que Bandeira revela, em seu poema, um comportamento totalmente de acordo com as premissas gerais das teorias freudianas aqui apresentadas resumidamente. Desde os primeiros versos, o poeta procura-de vários modos - recusar, involuntariamente, um fato traumático para seu ego. Essa recusa se manifesta, como acabamos de afirmar, de diversas maneiras: seja pela imediata reação de negar a morte do amigo, diante da trágica notícia recebida; seja pela insistência com que o poeta substitui o termo morte por ausência (cujo cabedal semântico pressupõe, entre outras coisas, a reversibilidade, marcada por uma possível presença); seja ainda pela conclusão do poeta no sentido de que a vida do amigo continua na obra que este deixou como indelével legado. Mas o indício mais forte de que o poeta realiza todo um processo de recusa como mecanismo de defesa do ego é a permanência, nas três partes do poema, da idéia de que o mesmo não estaria, naquele momento preciso, sentindo a falta do amigo falecido: com efeito, rejeitar um sentimento reconhecidamente traumatizante, como é o da saudade (correspondente aqui a um sentimento da falta de alguém), parece ser um vestígio autêntico desse fato.

Apenas para melhor exemplificar o que aqui vimos afirmando, atente-se para o impacto causado pela justaposição de dois versos essenciais do poema em questão, os mesmos que iniciam as primeira e terceira partes:

Anunciaram que você morreu [...]

Você não morreu: ausentou-se.

É inegável a intenção clara do poeta no sentido de negar veementemente a morte do amigo, negação esta que se manifesta antes como inconsciente recusa. 19

A afirmação acima nos remete diretamente ao segundo componente ressaltado - há pouco - na poesia de Bandeira: a coexistência de elementos do consciente e do inconsciente do autor. Mais do que os estudos realizados por Freud, são agora algumas das teorias elaboradas por Jung sobre a relação entre a poesia e a psicologia que nos irão auxiliar na compreensão deste fenômeno.

19 Convém atentar para a confusão que, vez por outra, é feita em relação a dois conceitos elaborados por Freud, os quais, apesar de semanticamente próximos, devem permanecer essencialmente distintos: trata-se da recusa (Verleugnung), "modo de defesa que consiste numa recusa pelo indivíduo de reconhecer a realidade de uma percepção traumatizante" e da negação (Verneinung), "processo pelo qual o indivíduo, embora formulando um dos seus desejos, pensamentos ou sentimentos, até ai recalcados, continua a defender-se dele negando que lhe pertença". O segundo termo não se aplica ao caso do poema aqui analisado. (Cf. LAPLANCHE, J. ; PONTALIS, J. B. Vocabulário da psicanálise. São Paulo: Martins Fontes, 1988). 
Com efeito, tendo o cuidado de ressaltar a importância da obra de arte independente de seu criador, Jung defende dois processos diferentes de criação, por meio dos quais toda obra há de se manifestar: os chamados modo psicológico e modo visionário de criar. $O$ primeiro estaria francamente ligado às experiências do cotidiano - portanto, ao consciente do autor -, podendo por isso ser facilmente detectado pelo crítico. $\mathrm{O}$ segundo, ao contrário, estaria visceralmente ligado aos elementos anímicos - portanto, ao inconsciente do autor -, sendo, por sua vez, de mais difícil apreensão por parte do crítico; além disso, a criação visionária teria uma relação necessária com a vivência originária do artista, algo que não tem correspondência na experiência real, sendo portanto a "expressão de uma essencialidade desconhecida,"20.

Sem nos demorarmos nas relações - ainda mais profundas - que Jung estabelece entre o fato poético e a Psicologia, não há como negar, também aqui, uma visível conexão entre a teoria junguiana e estes novos aspectos da poesia de Bandeira. Mas esta ligação, há que se ressaltar, assume uma surpreendente originalidade na pena do grande poeta: é que, em Bandeira, pode-se claramente perceber a manifestação concomitante dos dois modos de criação explicitados pelo pensador suiço. De fato, sua poesia contém tanto elementos de natureza psicológica - os conteúdos do consciente artístico - quanto elementos de natureza visionária - os conteúdos do inconsciente artístico.

Com efeito, para revelar o lado consciente da criação do poeta, concorrem os diversos elementos do cotidiano com que o mesmo ordena, prosaicamente, sua poesia: a mesa em que conversam sobre assuntos banais, o hotel em que o poeta se hospeda, a mundana chacrinha de São Roque, as situações variadas do dia a dia em que se encontra Bandeira e até os seus sentimentos mais facilmente perceptíveis. São, todos eles, "conteúdos que se movem nos limites da consciência humana" ou, em outros termos, "tema(s) captado(s) pela alma do poeta (e) elevado(s) a partir de uma vivência banal, à altura de sua vivência interior", como afirma o próprio Jung ao explicitar melhor o modo psicológico de criação. 21

Mas é possivel apreciar também, no poema de Bandeira, elementos próprios de seu inconsciente, alguns dos quais já evidenciados aqui pela aplicação das teorias freudianas à mesma peça. Neste sentido, a própria recusa manifestada - inconscientemente - pelo poeta, a que acrescentaríamos a relutância em aceitar o traumatizante sentimento de saudade ("agora não sinto a sua falta") ou a criação de situações comuns aos dois amigos, num claro processo

20 JUNG, C. G. "Psicologia e poesia". In: O espírito na arte e na ciência. Petrópolis: Vozes, 1991. p. 73-93.

21 lbid., p. 77. 
de fuga da realidade indesejável ("Direi: Faz tempo que ele não escreve./Irei a São Paulo: você não virá ao meu hotel./Imaginarei: Está na chacrinha de São Roque") são elementos próprios do modo visionário de criar.

Com efeito, é fácil perceber a relação formal que o consciente e o inconsciente estabelecem na poesia de Bandeira: por trás da aparente simplicidade que se manifesta no prosaísmo deliberado do autor, esconde-se todo um complexo universo de experiências interiores, irredutíveis a uma apreensão imediata por parte do leitor. Em outras palavras, o visionário (inconsciente) oculta-se no psicológico (consciente), corroborando uma das maneiras mais

frequientes de os dois níveis aqui tratados se relacionarem ${ }^{22}$ e evidenciando uma das principais características estilísticas de Bandeira: a ocultação do complexo e sublime pela humilde simplicidade. ${ }^{23}$

\section{Conclusão: a morte como geratriz}

Sem ter tido grandes pretensões em relação ao desvendamento do significado profundo da poética bandeiriana, nossa análise parece, contudo, ter revelado elementos importantes para uma melhor compreensão da expressão artística do grande poeta, com o que consideramos crumprida pelo menos parte da tarefa a que nos propusemos realizar neste ensaio.

Cabe contudo, algumas últimas e inevitáveis considerações.

Vimos, a partir de uma análise da macro e da microestrutura do poema em causa, a emergência de alguns componentes essenciais do mesmo, os quais se traduzem - a nosso ver - em duas espécies distintas de manifestação: a recusa da realidade e a coexistência (conflituosa ou não) de elementos do inconsciente e do consciente do artista. A partir desta primeira distinção, procedemos no sentido de explorar fatos e atitudes descritas - em maior ou menor grau - por teorias de natureza psicanalítica, a fim de salientar uma possível relação entre a poesia de Bandeira e a Psicanálise, trabalho que ainda aguarda um maior empenho por parte da crítica. Não obstante, resta-nos fazer por fim as seguintes observações: como já sugerimos anteriormente, em meio aos vários elos de ligação que se pode verificar entre as partes do poema, destaca-se um elo de

22 Cf. SILVEIRA, Nise da. A obra de arte e o artista. In: Jung. Vida e obra. Rio de Janeiro: Paz e Terra, 1984. p. 155-169, para quem "muitas vezes idéias oriundas de planos profundos do inconsciente insinuam-se desapercebidas em meio às coisas cotidianas".

23 Cf. ARRIGUCCI, Jr., Davi. Humildade, paixão e morte: a poesia de Manuel Bandeira. São Paulo: Companhia das Letras, 1990; Id., O humilde cotidiano de Manuel Bandeira. In: SCHWARZ, Roberto. Os pobres na literatura brasileira. São Paulo: Brasiliense, 1983. p. 106-122. 
natureza puramente temporal - um dos sustentáculos do poema, neste sentido, é exatamente o advérbio de tempo (agora) repetido nas três partes do mesmo e atuando como uma espécie de ponto de equilíbrio de toda a peça. Assim, a ênfase dada pelo poeta à temporalidade da poesia, faz todos os demais elementos se ofuscarem, obrigando o leitor a concentrar-se num único fato: o de que agora ele não sente sua falta, apesar de o poeta saber que um dia sentirá saudades do amigo ("sei bem que ela virá") e de ter a certeza de sua ausência ("Saberei que não, você ausentou-se").

Outro elemento a ser ressaltado, a título de conclusão: embora se trate de uma morte alheia, o poema se mantém centrado o tempo todo na figura do narrador (o eu-lírico), revelando assim uma profunda concentração emotiva tão profunda que nos caberia perguntar, não fosse a desimportância dessa questão para a fruição lírica da peça: de quem afinal trata o poema, de Mário de Andrade, como diz o título, ou de Manuel Bandeira? Evidentemente, esta é uma questão de somenos. Nem por isso devemos fechar os olhos diante do dissimulado esforço do poeta em concentrar em si mesmo toda a emotividade da obra, o que redimensiona nossa leitura da peça em questão: se o título e inúmeras passagens sugerem que se está tratando basicamente do amigo, uma leitura mais atenta nos revela ser o próprio eu-lírico o objeto de atenção privilegiado.

Estas observações - reveladoras, talvez, de mais alguns aspectos do inconsciente bandeiriano - apenas reafirmam a possibilidade e a necessidade de se articular agora e sempre um discurso psicanalítico com a finalidade expressa de desentranhar de sua obra o que ali subjaz de mais recôndito, já que, sobre todos os aspectos, ela se revela cada vez mais surpreendente: como no caso do poema aqui analisado, em que - num curioso e inesperado processo dialético da mais profunda tristeza causada pela morte, nasce a poesia.

\section{RESUMO}

O presente artigo analisa a relação entre psicanálise e literatura, procurando abordar a temática da morte na poesia de Manuel Bandeira, além de possibilitar abordar sua produção sob a perspectiva psicológica. cologia.

Palavras-chave: Psicanálise, literatura, Manuel Bandeira, poesia, morte, Psi- 


\begin{abstract}
The present article analyses the relations between psycho-analysis and literature, specially in Manuel Bandeira's poetry. The psycho-analytical perspective reveals the powerful dimension of death in this poet, and permits an original reading of his work.
\end{abstract} chology.

Key words: Psycho-analysis, literature, Manuel Bandeira, poetry, death, Psy- 